\title{
The Freshman-Sophomore Library at Minnesota
}

Mr. Rohlf is librarian, Freshman-Sophomore Library, University of Minnesota.

$\mathrm{O}$

N JANUARY 7, 1952, the University of Minnesota opened a new FreshmanSophomore library. The library occupies the entire ground floor (approximately 9I 50 sq. ft.) of Johnston Hall, a new classroom and administrative building situated next to the main library and connected with it by a tunnel.

This library is another of the many new open shelf reading rooms springing up throughout the country and it embodies many of their now accepted methods and ideas together with a few methods and ideas developed locally.

For some time there was felt a need at the University of Minnesota for a more direct way of providing library service to undergraduates, especially during their first year or two in college. A survey of the use of the circulation service, made early in I95I, revealed that while Freshmen and Sophomores constituted nearly one-third of the enrolment at Minnesota, they accounted for only one-fifth of the recorded library use. This new library then was organized as a modest beginning toward bringing new students closer to the library materials they will need to use immediately by making them more conveniently available in an attractive, open-shelf reading area.

Although the major clientele for this library is the freshman and sophomore student body of the university (numbering approximately 5000 in 1952 ) the use of the reading room and its collection is not rigidly restricted to this group. In the first six months of service it is estimated that total attendance has been close to 60,000 .

The freshman-sophomore library has a seating capacity of 270 students; study table and chairs for 250 and lounge type reading chairs for an additional 2o. There is space for an additional 50 study chairs if necessity does arise to increase the study facilities.

The collection, which consists mainly of books with a few pamphlet materials, is housed on excellently lighted open shelves in the center of the room. The study tables flank both outside walls to get the full benefit of natural light, with a wide area between the tables and the shelves serving as a corridor.

The service desk is located to one side of the entrance, and, by means of separate entrance and exit doors, all exit traffic flows past the service desk and out into a central hall.

The new collection is still relatively small, with fairly liberal duplication; but it is being built up steadily and is being broadened as the budget permits. At the present the concentration is in the humanities and social sciences, since separate chemistry, geology, engineering, physics, mathematics and biological-medical libraries serve the natural sciences. There are now some 3800 separate titles and over 5000 volumes, all selected for this special library.

Of the original book stock, largely based on faculty recommendations, for freshman and sophomore needs, approximately I 500 volumes were transferred from the general 
library on semi-permanent loans, and 3000 volumes were ordered specifically for this library. Since opening, orders have been placed for an additional i 500 volumes.

The collection is not arranged by a standard library classification scheme, but rather on shelves representing subjects taught in the main teaching departments of the university, such as English, geography, political science, etc. Within each department group the books are arranged by author and there is assigned to each book an accession number which also serves as a circulation number.

The public catalog is an author, or main entry catalog, serving only as an official guide to holdings, but not as a title or subject approach to the collection. The open shelves, together with the major departmental arrangement of material, appear to serve as a sufficient guide, at least while the collection stays of modest size.

The library also contains a small but workable reference collection which is on open shelves. This collection receives a heavy amount of use both by students who help themselves to the material they need, and by those.who ask for help from the librarian.

The staff is small, one librarian, with both full and part-time clerical help, but because of the simplified records and processing routines employed (all processing is done here rather than in the main university library), it is sufficient.

There have been several interesting trends developing since the library opened. One of the most important was the change in attitude toward reserve material by most professors. Previously most faculty members had placed large amounts of material on a restricted reserve basis in order to keep graduate students from tying up the material for a long period of time. With the opening of this library-and incidentally after a rather intensive campaign by the librarian-very few professors place more than two or three titles on reserve, and most do not have a reserve list. Rather, they concentrate on broad general assignments from any number of books and ask the students to read one or two of them, allowing the student to make his own choice from the open shelves. The results to date have been satisfactory.

The virility of the collection is attested to by the fact that circulation in only six months was equivalent to three times the number of volumes in the library. This does not include the heavy unrecorded use of material in the room, directly from the open shelves, but only the material actually signed for. In view of our small number of restricted reserve titles (at the most only 500 volumes for all the freshmansophomore classes, with an average of 250 volumes) it appears that these students are doing much more reading and much wider reading than before. For the small but fluctuating reserve collection the policy is fluid, with most titles on a one-day basis and placed on the open shelves. During final week they are restricted to two hours and placed behind the service desk. The loan period for the non-reserve material, which represents over 90 per cent of the total library collection, has been one week with almost unlimited renewals, and has resulted in a much quicker turnover of material than the more standard two week loan.

The use of the library has been constantly rising. By the end of spring quarter over 800 students a day were using this library, as compared to approximately 400 in January, and $500-600$ in April. Some of this is probably attributable to the pressure of final examinations.

Unlike the general library, the freshmansophomore library is open only from 8 a.m. until 6 p.m., Monday through Friday, but with liberal overnight and week-end 
loan privileges. By making the material easier to obtain and withdraw, it was believed that these hours would be satisfactory. This seems to be the case.

In order to obtain the student reaction to these variants from the policy of the main university library, and also to obtain their reactions to the library in general, a short questionnaire was submitted to sample classes of students towards the end of the spring quarter. The results were both helpful and gratifying.

Eighty-nine per cent of the students approved the service schedule and observed that the more generous loan privileges of reserve and non-reserve material made it unnecessary to visit the library evenings or Saturdays.

Eighty-two per cent of the students in these classes (which also contained some juniors and seniors) had used the library, and over one-half used it at least once a week. The results seem to reveal that those who do use the freshman-sophomore library, use it more than they do the main library, even though the freshman-sophomore library contains only books.

The main complaint mentioned in the replies was that the library was not open to general use by all students as it was to the freshmen and sophomores. This is because upperclassmen are encouraged to borrow books from the main library which does have other copies of most titles stocked in the freshman-sophomore library.

This then is a beginning at Minnesota toward bringing undergraduate students into closer contact with library materials. The present intention is to keep a moderately sized but active collection on hand within each department area. Books superseded or no longer useful will be withdrawn and replaced by newer material, with research playing no part of this library's objective. In line with this objective, loans from the freshman-sophomore library are not made to faculty or staff members of the university, but only to students.

There has been a strenuous attempt at streamlining records and files and it has allowed the library to be staffed lightly and yet to give service to patrons. By means of tickler files, carbon insert circulation forms, and other time saving forms, our records are simple to maintain, yet sufficient and accurate.

It appears that the library has been relatively successful. There are many small problems to be ironed out, but with modifications and changes as time goes by, together with the allowance for new developments, it should definitely prove an excellent as well as an economical way of bringing student and book together.

\section{University Library Buildings (Continued from page 157)}

lated environment. Further study of the libraries of institutions of higher education in the United States, of the public libraries in the United States, and even of the libraries of other countries would be needed to fill out the picture.
The study of university library buildings built in the United States between I84I and I 889 would also have a great deal to add to both the history of university library architecture and perhaps to the history of architectural development in the nation. 